\title{
Research on Brand Building Strategy of E-commerce Platforms for Agricultural Products
}

\author{
Li Xuewei \\ Department of Economic and Management \\ Wenhua College \\ Wuhan, China \\ shervie_lee@qq.com
}

\begin{abstract}
This paper does research on how to build agricultural products' own brands in the diversified e-commerce platforms through the rapidly developing agricultural product ecommerce platforms. This paper takes the brand of the agricultural product e-commerce platform as the research object, analyzes the existing e-commerce platform, and sums up the construction strategy of the brand of the agricultural product ecommerce platform. First of all, through the analysis of the development environment of e-commerce brands and the development of e-commerce platforms for agricultural products, this paper puts forward the problems in the development of the e-commerce platform of agricultural products and the trend of future development. It is hoped that through the research and suggestions of the brand of the agricultural product platform, we can give a certain theoretical guidance to the propaganda of the regional or national brands of agricultural product platforms.
\end{abstract}

Keywords-Agricultural products; Brand building;E-commerce platforms; Cold chain logistics

\section{INTRODUCTION}

Brand is a relative factor to measure the popularity and influence of an enterprise. In the household platform, the ecommerce platform of agricultural products is to survive in the seam, and it is self-evident to the brand. It is not possible to build a new brand image for the development of e-commerce. Yi. Especially at present, the agricultural product practitioners lack the brand consciousness and the operation condition is not good. Thus, it is the right time to build the brand of the agricultural product platform.

In recent years, the development of rural electric business presents a blowout feature. With the rapid development of ecommerce, the agricultural product e-commerce platform is emerging. The main driving force for the rapid development of agricultural products providers focuses on three aspects, one is the good economic environment. National income is stable for a huge purchasing power. Two is a stable social environment. The continuous maturity of the Internet and the wide use of network applications provide a good foundation for the agricultural product business. The continuous improvement and development of cloud application, big data and mobile payment provide good technical support for ecommerce of agricultural products. Three is the guidance of the policy. The "three rural" issue is the key issue of the

The study was supported by the humanities and social sciences research project of the Hubei Provincial Department of Education (No.17G102) central No. 1 document in the last ten years. In the last two years, many policies related to the electronic commerce of agricultural products have been introduced. These all show the importance of the government to the e-commerce of agricultural products.

\section{THE DEVELOPMENT TREND OF THE E-COMMERCE PLATFORM FOR AGRICULTURAL PRODUCTS}

\section{A. The scale of e-commerce of agricultural products continues to expand}

The future development of agricultural products ecommerce platform will inevitably have the trend of scale expansion. In the pace of the slow progress of agricultural products, the government supports the development of the agricultural products, which is a good way for rural development under the policy of accurate poverty alleviation advocated by the president in recent years. According to statistics, the average annual growth rate of agricultural products online sales in 2014 to 2016 reached $40 \%$.

\section{B. Agricultural product electric business drives rural e- commerce development}

Agricultural products e-commerce first led to the development of rural soil products towards the city. Secondly, the development of rural agricultural products not only reduce the risk of unmarketable agricultural products, but also drive the rural areas into e-commerce and community-based development. Rural e-commerce is the same progress, in many rural areas, the development of $3 \mathrm{G}$ mobile, $4 \mathrm{G}$ mobile, broadband and TV integration, and gradually formed a lot of Taobao villages and towns. Thus it can be seen that the agricultural products have driven the pace of the development of the rural e-commerce, and the villagers can easily buy many daily necessities, that is, the rural development and the life of the people in the region. 


\section{The cold chain logistics of agricultural products will be fully developed}

After the development of agricultural products for many years, it has gradually found the disadvantages of cold chain logistics, and will try to improve the logistics system so as to make the electric business of agricultural products have no fundamental resistance in logistics. The cold chain logistics is fully marked by: first, cost reduction; two, efficiency improvement; three, quality improvement. In fact, no matter which aspect of the development of the electricity supplier, it is essential to improve the logistics system, and the agricultural product providers only have higher requirements for logistics.

\section{Online and offline fusion of agricultural products}

The online transaction of agricultural products ecommerce line is inseparable from logistics. The development of agricultural products will achieve seamless connection under the online and offline businesses. Online relying on ecommerce platform, consumers can be very convenient to choose the products they need, and the offline transaction is based on the entity store, consumers can choose the real store and buy products on the Internet. In this way, the agricultural product e-commerce platform will combine the online and offline businesses, which not only guarantees the user's traffic, but also brings consumers a better consumption experience.

\section{THE EXISTING PROBLEMS OF THE BRAND CONSTRUCTION OF THE E-COMMERCE PLATFORM FOR AGRICULTURAL PRODUCTS}

The brand construction of a platform includes all aspects, not only in brand positioning and brand communication, but also on the most important aspects of the platform itself in platform construction and platform brand awareness. Brand construction includes brand positioning, brand planning, brand image, brand advocacy and brand values. In the business platform industry, we all know that the agricultural products ecommerce is a primary child, but it has an enviable background in the first appearance, relying on the big environment of e-commerce, the agricultural product ecommerce is advancing steadily. But at the same time, we can also find that there are many deficiencies in the development of agricultural products, which need to be adjusted and corrected.

\section{A. The consciousness of the platform brand is weak}

Nowadays, e-commerce platforms have sprung up in this industry. The major platforms are Jingdong, Tmall and so on. When we want to buy electronic products, the first thing we think about is Jingdong. The first thing we think about is Tmall. Wait 。 However, when we want to buy some agricultural products on the Internet, we often do not have a good familiar platform to recommend. From this, we can see that the brand awareness of the e-commerce platform for agricultural products is very weak, and some platforms have not yet realized how important the brand competition is in the enterprise competition, or some platforms are aware of it, but have no ability or way to better develop their own platform brands. Here, in the rapid development of the e-commerce platform, especially when the development of the agricultural products is gradually accelerating, the awareness of the platform for the development of the brand will become more and more important. This will be a strong competitive factor in the e-commerce platform of the future agricultural products.

\section{B. The positioning of the platform brand is not clear}

Brand positioning is in the market with many brands to clear the positioning of the enterprise, clear consumer groups, only a clear positioning to let consumers feel the difference in goods, can be recognized by consumers, so that the enterprise will not be oblivion in the vast market. Moreover, the agricultural products e-commerce platform is not yet mature, and there are too many places to pay attention to and improve. The first thing to pay attention to is the positioning of the platform brand. The brand positioning of a platform includes positioning of products, positioning of consumers' target groups, etc. And product positioning is mainly embodied in a platform of product categories, e-commerce platform, especially the agricultural products e-commerce platform without clear product positioning is difficult to have a very high consumer stickiness, as the fourth chapter will talk about the case I buy net, no clear flat platform brand positioning, the business platform in this line It's hard to stand out in the industry. Only by giving a clear and correct brand positioning can the dazzled consumers make clear what they want to find, find the brand they need, and create greater profits for the enterprises.

\section{The problem of brand communication on the platform}

Brand communication is actually a process from brand to consumer, and is a consumer oriented. Through traditional hard advertising to today's soft advertising, brand communication is gradually shifting from brand owners to consumers. For an e-commerce platform, brand communication is more important. Because most of the ecommerce platform as a platform for a third party, the need to rely on the popularity of a large number of customer traffic, and brand communication is the way to bring the popularity of the platform. Because at present, there is no agricultural product platform with high popularity, which leads to the failure of the platform flow, the platform can not play the brand effect, the platform brand development is slow. Therefore, the platform is still very necessary for the step of brand communication. Brand communication will help to increase the trust of the consumer to the brand of the enterprise, thus improve the consumer's purchase intention and increase the long-term profit of the enterprise.

\section{The problem of brand management of platform}

The brand management of a platform includes a series of brand asset systems, such as the value of the platform brand, the optimization of the platform brand, the culture of the platform brand, the extension of the platform brand and so on. The agricultural products business platform can only achieve steady and sustainable development by doing relevant work on brand management. 


\section{1) The brand value of the platform}

The value of the brand is determined by the value of the brand. Generally speaking, reputable brands with good reputation are intangible assets of an enterprise or brand. However, as far as the current agricultural products ecommerce platform appears, its platform brand value is not high, at least not Jingdong, No. 1 store and other well-known platform value. Although the short term of the agricultural product e-commerce platform is a reason, the main reason is because the platform itself is not perfect, and the brand value of the platform is not yet fully mature.

\section{2) The platform brand optimization problem}

For an innovative agricultural product platform, it is required to have a perfect brand image like the Tmall Jingdong, but it can not be retreated because of the difficult road ahead. Especially for the "rich two generation" such as I buy the net, the big tree which depends on the behind is good for the cool, but it is absolutely impossible to improve the power of the platform brand. A platform brand needs to be constantly optimized after it is created, so as to open up the brand awareness of the platform so as to attract a large number of customers' traffic.

\section{3) The cultural problems of the platform brand}

Brand culture refers to the gradual accumulation of culture in the operation of a brand. It is a concept of emotional identification between consumers and consumers. And the brand culture of the agricultural product platform is to let consumers have a sense of trust on the agricultural product platform, but obviously, the current agricultural product platform does not have this ability. This is the first thing we want to buy from Jingdong, Tmall and so on.

\section{4) The extension of the platform brand}

The ultimate goal of creating and optimizing brand is to continuously acquire better sales and profits. Because the duplication of intangible assets is not cost - free, it leads to the blind expansion of the product types of some agricultural products platform, resulting in the rapid expansion of the platform, and the consumers can not quickly accept the transformation of the platform and lose the customer's flow.

\section{SUGGESTIONS ON THE CONSTRUCTION OF THE BRAND OF AGRICULTURAL PRODUCTS}

Brand is the image embodiment of a product, and the product is the material carrier of the brand. A brand is the performance of the product and service quality of an enterprise, and it is an important symbol distinguishing from other enterprises. The stage of brand building includes brand positioning, brand communication, brand extension and brand loyalty. In addition to several stages of brand building, brand building includes the creation of the image of the platform itself. Not to mention, the process of building a brand is the process of continuous innovation of the enterprise. Only after the enterprise has the brand, which is vital to the competition, can be invincible.

\section{A. Set up the awareness of the platform brand}

Traditional consumers do not pay much attention to brand names, they only focus on product names, but now consumers are different. After the rapid economic development in China, consumers now have more and more emphasis on brand, from the past brand preference to brand or famous brand products. Therefore, for the present, the development of agricultural product platform brand is essential. Then the first thing to do is to deepen the impression of the brand image in the consumer's mind, and the second is to do a good job of the long time brand reputation accumulation. The most important thing is to grasp the quality assurance of the platform products and strengthen the consumer after sale guarantee. A good agricultural product platform brand, only in the process of publicity to ensure the quality of the brand, in order to set up a good brand image in the heart of the consumer.

\section{B. Shaping the brand culture of the platform}

Brand culture is the core of brand building. A good brand must have a good brand culture. Because only by creating a good brand culture can we occupy the core position of brand in brand building. And the brand culture molding includes three aspects: first, the basic brand image design, including brand self-improvement, brand slogan, brand mascot, and so on; second, design and perfect brand promotion strategy, including advertising in all aspects; third, the significance of the rich brand extension, which includes brand protection, call We have perfect planning and good response.

The successful molding of brand culture is the most important step of brand building. The brand culture carries the development idea of the enterprise, and it is the motive force that the enterprise can continue to develop in the market. With the development of agricultural products, brand is becoming more and more important foothold and means of competition nowadays. Brand culture is formed in the process of brand creation, growth and development. It is an important combination of brand and corporate culture.

\section{Do a good job in platform brand publicity}

Brand communication is the foundation of brand building and a process of organically linking enterprises, brands and consumers. In addition to the original positioning brand, brand communication is an important hurdle to enhance the corporate image. There are a variety of ways of brand communication. According to the traditional brand communication, it can set up site publicity, posters and so on. At present, more is video publicity, including TV advertising, website advertising, video advertising and so on. For the current agricultural products e-commerce platform, popularity and trust is far more than the Jingdong, Tmall and other platforms, therefore, at this time the publicity of the platform brand is particularly important. Brand publicity spreads the image of the platform and the brand culture. A good platform brand 
publicity is the foundation of the brand development of the agricultural product e-commerce platform.

\section{Strengthen the brand management of the platform}

\section{1) Upgrade the image of the platform}

In addition to the original positioning brand, brand communication is an important hurdle to enhance the corporate image. But the platform brand of agricultural products is a special kind of electronic business platform, and the most important thing should be the quality of products. Good product quality can enhance the image of platform products and platforms in the minds of consumers at the first time. Because only if we have a good product variety and lay a solid foundation can we produce a good brand. As a product with great reputation, the quality of agricultural products is the first priority. But to do this is not so easy, the first is the logistics problem, the speed of logistics directly affects the taste of the product, the next is the cold chain supply chain problem, the cost of the general small enterprises in this is too large, which leads to the more exiting of the producers of agricultural products.

\section{2) Perfect the construction of the platform brand}

For the brand development of the agricultural product ecommerce platform, the platform is long and patient maintenance after initially positioning the appropriate brand characteristics and culture. Manage a platform brand, including its brand value, brand optimization, brand extension and so on. After starting from Tmall Jingdong, the commercial platform of agricultural products started in front of the pearl jade. It wants to establish an excellent platform brand. It needs the platform to maintain the brand and optimize the brand. It is the good impression that the platform brand has gradually left in the consumer's mind.

\section{CONCLUSION}

This paper analyzes and collate the existing documents, and uses qualitative analysis and summary to find out the problems of the construction of the agricultural product platform brand and put forward the corresponding strategic suggestions.

\section{REFERENCES}

[1] Li Ying, Wei Hao. Research on the development strategy of agricultural products based on e-commerce platform [J]. rural economy and technology, 2016, 27 (22):68

[2] Zhao Hao, Zhao Yilin. Current situation and Countermeasures of agricultural products e-commerce development $[\mathrm{J}]$. cooperative economy and technology, 2017 (15): 124-125

[3] Li Xuexin, Li Haipeng. Summary of China's brand positioning theory [J] Journal of Liaoning University (PHILOSOPHY AND SOCIAL SCIENCES EDITION), 2012, 40 (03): 100-106

[4] Yue Wan Xing. Research on brand building of Internet search engine [Master's Thesis]. Beijing: Capital University of Economics and Business library, 2014

[5] Jiang Qian Wen. Research on the development of agricultural product ecommerce under the background of the Internet. [J]. China's strategic emerging industries, 2017, (12): 13-14

[6] Lee T Y, Bradlow E T. Automated marketing research using online customer reviews[J]. Journal of Marketing Research.2011,48(5),881-894 